\title{
EGFR mutation status in a series of Turkish non-small cell lung cancer patients
}

\author{
GIZEM CALIBASI-KOCAL ${ }^{1}$, ARSALAN AMIRFALLAH ${ }^{2-4}$, TOLGA SEVER $^{1}$, OLCUN UMIT UNAL ${ }^{5}$, \\ DUYGU GUREL $^{6}$, ILHAN OZTOP ${ }^{7}$, HULYA ELLIDOKUZ $^{8}$ and YASEMIN BASBINAR ${ }^{1,9}$ \\ ${ }^{1}$ Department of Translational Oncology, Institute of Oncology, Dokuz Eylul University, Izmir 35340, Turkey; \\ ${ }^{2}$ Biomedical Center, Faculty of Medicine, University of Iceland; ${ }^{3}$ Cell Biology Unit, Department of Pathology, \\ Landspitali University Hospital, 101 Reykjavik, Iceland; ${ }^{4}$ Department of Basic Oncology, Institute of Oncology, \\ Dokuz Eylul University, Izmir 35340; ${ }^{5}$ Bozyaka Education and Research Hospital, Division of Medical Oncology, \\ Department of Internal Medicine, University of Health Sciences, Izmir 35170; Departments of ${ }^{6}$ Pathology and \\ ${ }^{7}$ Medical Oncology, Faculty of Medicine, Dokuz Eylul University; ${ }^{8}$ Department of Preventive Oncology, \\ Institute of Oncology, Dokuz Eylul University, Izmir 35340; ${ }^{9}$ Personalized Medicine and \\ Pharmacogenomics/Genomics Research Centre, Izmir 35350, Turkey
}

Received January 8, 2020; Accepted May 6, 2020

DOI: $10.3892 /$ br.2020.1308

\begin{abstract}
Epidermal growth factor receptor (EGFR) mutations are potential markers driving carcinogenesis, and may alter the response to EGFR tyrosine kinase inhibitors in patients with non-small cell lung cancer (NSCLC). The frequency of EGFR mutations in patients with NSCLC differs according to sex, smoking habits and regional-based ethnicity differences. The aim of the present study was to determine the frequency of EGFR mutations in Turkish patients with NSCLC to highlight the importance of regional differences, and their associations with patient characteristics. Genomic DNA was extracted from formalin-fixed and paraffin-embedded tumor tissue sections of 409 NSCLC patients. The most common EGFR mutations in exons 18, 19, 20 and 21 were detected using BioFilmChip-based microarray assay. The overall EGFR mutation frequency was $16.6 \%$, and the highest mutation frequencies were observed in exon $19(6.4 \%)$ and exon $21(7.3 \%)$. There was a higher frequency of EGFR mutations in females compared with males and in never-smokers compared with smokers (both $\mathrm{P} \leq 0.05$ ). These results were similar to other European population-based studies, but not consistent Middle-Eastern based studies. The present study may contribute to understanding the gradient frequency of $E G F R$ mutation across different ethnicities, and in designing genome wide-based collaborations that may reveal novel decision making and susceptibility mutations in EGFR in patients with NSCLC.
\end{abstract}

Correspondence to: Professor Yasemin Basbinar, Department of Translational Oncology, Institute of Oncology, Dokuz Eylul University, 1606 Mithatpasa street, Inciralti, Izmir 35340, Turkey E-mail: yasemin.baskin@deu.edu.tr

Key words: non-small cell lung cancer, epidermal growth factor receptor, mutations, frequency, personalized medicine

\section{Introduction}

Lung cancer, the leading cause of cancer-associated death worldwide, is the most common type of cancer in both sexes (1). According to the latest Cancer Statistics Report published by the Turkey Ministry of Health in 2015, annual lung cancer rates for the Turkish population are 52.5 cases per 100,000 individuals in males, and 9.0 per 100,000 individuals in females (2).

Exposure to various environmental pollutants, such as smoking, radon, asbestos and air pollution, as well as family history and genetic background exert significant effects on the progression of lung cancer $(3,4)$. Non-small cell lung cancer (NSCLC) is the most common type of lung cancer, accounting for $85 \%$ of all lung cancer cases, and chemotherapy is the primary means of NSCLC treatment (5). In the past decade, the treatment protocols for patients with NSCLC have received important updates and additions (6). An increased understanding of the signaling pathways involved in NSCLC have shown that epidermal growth factor receptor $(E G F R)$ mutations are potential markers driving carcinogenesis, advanced survival and response to definite EGFR tyrosine kinase inhibitors $(7,8)$. EGFR is a transmembrane glycoprotein, and one of four members of the ERBB family of tyrosine kinase receptors. Auto-phosphorylation of receptor tyrosine kinase by EGFR initiates signaling pathways that regulate differentiation, metastasis, survival, angiogenesis and proliferation $(8,9)$. There are several mechanisms for aberrant activation of EGFR such as mutations, overexpression, ligand-dependent receptor dimerization and/or independent activation (10). EGFR mutations, primarily located in exons 18, 19, 20 and 21 , are widely present in patients with NSCLC, particularly in the adenocarcinoma subtype. The frequency of $E G F R$ mutations in NSCLC differs based on sex, tobacco exposure and ethnicity. The frequency of EGFR mutations 
in the Asian population is $40-60 \%$, which is higher than the $10-30 \%$ reported for non-Asian (Caucasian) populations (11). There are extensive amounts of data regarding the frequency of EGFR mutations in Asian and Western patients with NSCLC; however, the data available from patients of other ethnicities is not sufficient to evaluate the frequency of EGFR mutations based on the ethnicity in patients with $\operatorname{NSCLC}(7,8,11,12)$.

Turkey has a multiethnic population due to its geographic location between Europe and Asia continents and its proximity to the Middle-East. The aim of the present study was to determine the frequency of $E G F R$ mutation types in Turkish patients with NSCLC to highlight the importance of regional differences and their correlation with patient characteristics.

\section{Materials and methods}

Patients and tumortissue samples. A total of 409 formalin-fixed and paraffin-embedded (FFPE) tumor tissue samples of NSCLC adenocarcinoma patients between November 2012 and November 2017, were included in this retrospective study. All patients were diagnosed, followed-up and EGFR mutation testing was performed in the Dokuz Eylul University Hospital. Tumor specimens were evaluated by an experienced pathologist to confirm the NSCLC histology and tumor cell content. The inclusion criteria of the present study were as follows: i) Newly diagnosed and pathologically confirmed non-small cell adenocarcinoma; ii) FFPE tissue section contained $\geq 75 \%$ tumor tissue; iii) there was sufficient tumor tissue sample for molecular testing; iv) the anti-tumor treatment did not begin before sample collection; and v) informed written consent was obtained from patients. Exclusion criteria were as follows: i) Tissue section contained $<75 \%$ tumor tissue; ii) insufficient tumor tissue samples were excluded; iii) patients were receiving anti-tumor treatment at the time of sample collection; iv) cases with no informed consent. Based on these inclusion and exclusion criteria, 409 patients met the all criteria for inclusion. Tumor sections $(10 \mu \mathrm{m})$ were sectioned from each FFPE tissue block containing at least $75 \%$ tumor tissue for genotyping. Patient demographic data were obtained from the hospital records. This data included the age, sex, smoking status, primary tumor location and metastatic status. The present study was based on pathological archived material and was approved by Dokuz Eylul University, Non-invasive Researches Ethics Committee (Izmir, Turkey) (approval no. 300-GOA, 2011/28-03). Written informed consent was obtained from all patients. The present study also conformed to the principles outlined in the Declaration of Helsinki (13).

Patient characteristics. Based on the Open Source Epidemiologic Statistics for Public Health analysis results, a total of 409 NSCLC adenocarcinoma patients were included in the present study, and the clinicopathological characteristics of these patients are described in Table I. Of these patients, $73.1 \%(n=299)$ were male, $26.9 \%(n=110)$ of the female. The median age of all the patients was 60 years (range, 23-89 year) and 58.9\% of patients had a metastasis at the time of diagnosis. There were marginally more smokers among the patients $(60.1 \%$ ) and $60.6 \%$ of patients had tumors localized to the right lung.

The median age of the female patients was 57.7 years (23-89 years) and $53.6 \%$ of females were metastatic at the time of diagnosis. In total, $40 \%$ of female patients were smokers and $64.5 \%$ of female patients had right lung localized tumors. The median age of the male patients was 61 years (31-87 years) and $53.8 \%$ of males were metastatic at the time of diagnosis. In total, $67.9 \%$ of male patients were smokers and $59.2 \%$ of male patients had right lung localized tumors.

DNA extraction. Genomic DNA was extracted from $10-\mu \mathrm{m}$ thick tumor tissue sections using the QIAamp DNA FFPE Tissue kit (Qiagen, Inc.) according to the manufacturer's protocol. A total of 3-5 sections were used depending on the size of the tumor tissue in the section. Tissues were deparaffinized in xylene, washed with absolute ethanol and air-dried. The lysis process was performed using proteinase $\mathrm{K}$ at $56^{\circ} \mathrm{C}$ for $1 \mathrm{~h}$. Genomic DNA with a concentration of at least $15 \mathrm{ng} / \mu \mathrm{l}$ was required for genotyping; the quality and quantity of the extracted DNA was determined using a NanoDrop 2000 UV-Vis Spectrophotometer (Thermo Fisher Scientific, Inc.) (14).

EGFR mutation analysis. The INFINITI EGFR assay (AutoGenomics, Inc.) was used to detect the most common EGFR mutations in exons 18, 19, 20 and 21 (Table II). The INFINITI method is a BioFilmChip-based microarray assay, and the system is designed to detect fluorescence signals of labeled DNA targets hybridized to the chip. This assay includes several processes: i) DNA extraction from tumor tissue, ii) PCR amplification, iii) specific primer extension with fluorescent labels, iv) hybridization to BioFilmChip, and iv) signal detection using the built-in microscope and results presentation. The 'Zip-code' bound to allele-specific primers can only be extended with fluorescent labels if the specific primer matches with the wild-type or mutated DNA strand. After elongation of the mutated sequences for EGFR exons 18, 19, 20 and 21, and also the wild-type DNA strand, all Zip codes were hybridized to the designated area $(15,16)$. Briefly, genomic DNA (15-60 ng) was amplified by using PCR master mix (AutoGenomics, Inc.) in a total volume of $20 \mu \mathrm{l}$ and purified by using shrimp alkaline phosphatase and exonuclease I treatment SAP/Exo (Affymetrix/USB Products Inc.) on a thermal cycler (BioRad Laboratories, Inc.). The thermocycling conditions used were: $94^{\circ} \mathrm{C}$ for $2 \mathrm{~min}$; 10 cycles of $94^{\circ} \mathrm{C}$ for $15 \mathrm{sec}$ and $67-57^{\circ} \mathrm{C}$ for $15 \mathrm{sec}$ (the temperature was decreased by $1^{\circ} \mathrm{C}$ each cycle); followed by 30 cycles of $94^{\circ} \mathrm{C}$ for $15 \mathrm{sec}$ and $57^{\circ} \mathrm{C}$ for $15 \mathrm{sec}$. The SAP/Exo procedure was performed as three steps: i) at $37^{\circ} \mathrm{C}$ for $60 \mathrm{~min}$; ii) at $94^{\circ} \mathrm{C}$ for $20 \mathrm{~min}$; and iii) holding at $4^{\circ} \mathrm{C}$. The samples were analyzed using INFINITI Analyzer (Autogenomics Inc.) according to the manufacturer's protocol. Fluorescently labeled nucleotides were incorporated into the targets via allele-specific primer elongation on the INFINITI ${ }^{\circledR}$ analyzer (Autogenomics Inc.) then samples were hybridized to BioFilm chip microarrays (AutoGenomics Inc.). Scanning, signal detection and analysis were performed using INFINITI Qmatic 6.6 software (Autogenomics Inc.). One microarray chip was used for each case. 
Table I. Patient characteristics.

\begin{tabular}{|c|c|c|c|}
\hline Clinicopathological characteristics & Total & Female & Male \\
\hline Median age (range), years & $60(23-89)$ & $57.7(23-89)$ & $61(31-87)$ \\
\hline \multicolumn{4}{|l|}{ Smoker, \% (n) } \\
\hline Yes & $60.1(246)$ & $40(44)$ & $67.9(203)$ \\
\hline No & $35.9(163)$ & $60(66)$ & 32.1 (96) \\
\hline \multicolumn{4}{|l|}{ Tumor location } \\
\hline Right lung & $60.6(248)$ & $64.5(71)$ & $59.2(177)$ \\
\hline Left lung & $39.4(161)$ & $35.5(39)$ & $40.8(122)$ \\
\hline \multicolumn{4}{|l|}{ Age, $\%(\mathrm{n})$, years } \\
\hline$\geq 50$ & $82.2(336)$ & $77.3(85)$ & $83.9(251)$ \\
\hline$<50$ & 17.8 (73) & $22.7(25)$ & 16.1 \\
\hline \multicolumn{4}{|l|}{ Metastases, \% (n) } \\
\hline Yes & $58.9(241)$ & $53.6(59)$ & $53.8(161)$ \\
\hline No & $41.1(168)$ & $46.4(51)$ & $46.2(138)$ \\
\hline
\end{tabular}

Table II. Mutations scanned using the INFINITI analyzer.

\begin{tabular}{ll}
\hline Exon & Scanned EGFR mutations \\
\hline
\end{tabular}

Exon 18 Glu709 Ala; Glu709 Gln; Glu709 Gly; Glu709 Lys; Glu709 Val; Gly719 Ala; Gly719 Arg; Gly719 Cys; Gly719 Ser; Ser720 Phe

Exon 19 Lys739_Ile744dup; Lys745_Glu746del; Glu746_Ala750del; Glu746_Thr751delins; Glu746_Thr751delins; Glu746_Ala750delins; Glu746_Ala750del; Glu746 Lys; Glu746_Ala750delins; Glu746_Pro753delins; Glu746_Ser752del; Glu746_Ser752delins; Glu746_Thr751delins; Glu746_Thr751delins; Glu746_Ser752delins; Glu746_Thr751delins; Glu746_Ser752delins; Leu747_Glu749del; Leu747_Thr751delins; Leu747_Ser752del; Leu747_Ser752delins; Leu747_Pro753delins; Glu746_Glu749del; Leu747_Glu749del; Glu746_Thr751del; Leu747_Thr751del; Leu747_Thr751delins; Leu747_Lys754delins; Leu747_Pro753delins; Leu747_Ala750del; Leu747_Thr751del; Arg748_Thr751delins; Glu749_Thr751del; Thr751_Ile759delins; Ser752_Ile759del

Exon 20 Glu762insEAFQ; Glu762ins; Val769Met; Val769Leu; Asp770ins; Ala767_Val769dup; Asp770fs; Pro772Arg; Ser768_Asp770dup; His773Arg; His773Leu; Asn771_His773dup; Val774Met; Arg776Cys; Gly779Phe; Thr790Met

Exon 21 Asn826Ser; His835Leu; Leu858Arg; Leu858Met; Leu858Arg; Leu861Gln; Leu861Arg

$E G F R$, epidermal growth factor receptor.

Statistical analysis. The framework of Cancer Statistics Report of Turkey Ministry of Health, 'Open Source Epidemiologic Statistics for Public Health' (Available from, openepi.com/SampleSize/SSPropor.htm) was used to determine the required case numbers to include in the present study (17).

$\mathrm{R}$ version 3.4.3 was used for all statistical analysis (18). Descriptive statistics in $\mathrm{R}$ was used to analyze non-categorical clinicopathological characteristics. The frequency of clinicopathological characteristics such as smoking status, location of tumor, age group, metastasis status, EGFR mutations in exons 18,19, 20 and 21, characteristics of patients with EGFR mutations and detected EGFR mutations according to the exons were calculated in $\mathrm{R}$ using the table function. For calculating the percentage of categorical variants, the proportional table function results were multiplied by 100 . A
Table III. EGFR mutation frequency in exons 18, 19, 20 and 21.

\begin{tabular}{lcc}
\hline Exon & Mutant, \% (n) & Wild-type, \% (n) \\
\hline Exon 18 & $1.2(5)$ & $98.8(404)$ \\
Exon 19 & $6.4(26)$ & $93.6(383)$ \\
Exon 20 & $3.7(15)$ & $96.3(394)$ \\
Exon 21 & $7.3(30)$ & $92.7(379)$ \\
Multiple exon mutations & $2 \quad(8)$ & $98(401)$ \\
Overall & $16.6(68)$ & $83.4(341)$ \\
\hline
\end{tabular}

$E G F R$, epidermal growth factor receptor.

Pearson's $\chi^{2}$ test was used to assess the association between mutation status and clinicopathological characteristics. 
Table IV. Characteristics of patients with EGFR mutations.

\begin{tabular}{|c|c|c|c|c|c|}
\hline Characteristics & Total & Exon 18 & Exon 19 & Exon 20 & Exon 21 \\
\hline Median age (range), years & $63(39-89)$ & $66(53-76)$ & $59(39-77)$ & $63(48-78)$ & $65(51-78)$ \\
\hline \multicolumn{6}{|l|}{ Smoker, \% (n) } \\
\hline Yes & $47.1(32)$ & $20(1)$ & 26.8 & $86.7(13)$ & 50 \\
\hline No & $52.9(36)$ & $80(4)$ & $69.2(18)$ & $13.3 \quad(2)$ & 50 \\
\hline \multicolumn{6}{|l|}{ Sex, \% (n) } \\
\hline Female & $38.2(26)$ & $60(3)$ & $42.3(11)$ & $6.7 \quad(1)$ & $50 \quad(15)$ \\
\hline Male & $61.8(42)$ & $40(2)$ & $57.7(15)$ & $93.3(14)$ & 50 \\
\hline \multicolumn{6}{|l|}{ Tumor location, \% (n) } \\
\hline Right lung & $52.9(36)$ & $60(3)$ & $65.4(17)$ & $33.3 \quad(5)$ & $53.3(16)$ \\
\hline Left lung & $47.1(32)$ & $40(2)$ & 34.6 & $66.7(10)$ & $46.7(14)$ \\
\hline \multicolumn{6}{|l|}{ Age, $\%(\mathrm{n})$} \\
\hline$\geq 50$ & $88.2(60)$ & $100(5)$ & $73.1(19)$ & $100(15)$ & $100(30)$ \\
\hline$<50$ & $11.8 \quad(8)$ & $0(0)$ & 26.9 & $0 \quad(0)$ & $0 \quad(0)$ \\
\hline \multicolumn{6}{|l|}{ Metastasis, \% (n) } \\
\hline Yes & $51.5(35)$ & $60(3)$ & $50 \quad(13)$ & $40 \quad(6)$ & $56.7(17)$ \\
\hline No & $48.5(33)$ & $40(2)$ & $50 \quad(13)$ & $60 \quad(9)$ & $43.3(13)$ \\
\hline
\end{tabular}

$E G F R$, epidermal growth factor receptor.

$\mathrm{P}<0.05$ was considered to indicate a statistically significant difference.

\section{Results}

In total, 68 patients were detected with an EGFR mutation among the 409 patients with NSCLC. The overall frequency of all EGFR mutations was $16.6 \%$ (Table III). The highest mutation frequencies were detected on exons 19 and 21. The frequency of EGFR exon 19 mutations was $6.4 \%$ and the exon 21 mutation frequency was $7.3 \%$. The frequency of EGFR exon 18 mutations was $1.2 \%$ and for exon 20 it was $3.7 \%$. In total 8 patients $(2 \%)$ had multiple exon mutations; such as deletion of exon 18 and exon 19 mutations in the same patient (Table III). In these multiple exon mutations, exon 21 mutations were predominantly accompanied with other exon mutations. One patient had mutations in exon 18 and exon 19; three patients had mutations in exon 18 and exon 21 ; one patient had mutations in exon 19 and exon 21; and three patients had mutations in exon 20 and exon 21.

Table IV shows the characteristics of patients with EGFR mutations. In terms of smoking, $52.9 \%$ of all patients with mutations were non-smokers. The majority of exon 18 and 19 mutations were observed in non-smokers (80 and $69.2 \%$, respectively), but exon 20 mutations were considerably more common in smokers $(86.7 \%)$. Of the patients with mutations, $61.8 \%$ were male, exon 19 and 20 mutations were more commonly observed in male patients $(57.7$ and $93.3 \%$, respectively); however exon 18 mutations were commonly observed in females $(60 \%)$. The EGFR mutated NSCLC tumors were generally localized in the right lung (52.9\%), and exons 18, 19 and 21 mutated tumors were more commonly localized in the right lung (60, 65.4 and $53.3 \%$, respectively).

The presence of mutations were compared with the patient's characteristics. Table $\mathrm{V}$ shows the comparison of clinical characteristics of patients with EGFR-mutated tumors and $E G F R$ wild-type tumors. A significant correlation was found between non-smoking patients and overall EGFR mutation presence $(\mathrm{P}=0.002)$ and between female patients and the overall presence of $E G F R$ mutations $(\mathrm{P}=0.017)$. When the presence of exon 18 mutations was compared with patient characteristics, there was no correlation found with any of the other patient characteristics. For exon 19 mutations, EGFR mutations were found significantly more often in non-smoking patients compared with smokers $(\mathrm{P}=0.002)$. There was a significant correlation found between males and the presence of exon 19 mutations $(\mathrm{P}=0.047)$. Except for the primary tumor location, there were no other significant correlations found between exon 20 mutations and any other patient characteristics. Exon 20 mutations were significantly correlated with tumors localized in the left lung $(\mathrm{P}=0.031)$. Exon 21 mutations were correlated with sex and age. Female patients had a higher frequency of exon 21 mutations compared with males $(\mathrm{P}=0.004)$ and the mutation frequency of exon 21 was significantly higher in patients $>50$ years $(\mathrm{P}=0.011)$

Different mutation types were observed during the genotyping process (Table VI). For exon 18 and exon 21, only point mutations were detected. For exon 19, deletions were the most common mutation type, but indels were detected in 2 patients. Nearly all mutation types were observed in exon 20 , including point mutations, insertions, duplications as well as multiple different types of mutations. The specific mutations observed are listed in Table VI. 


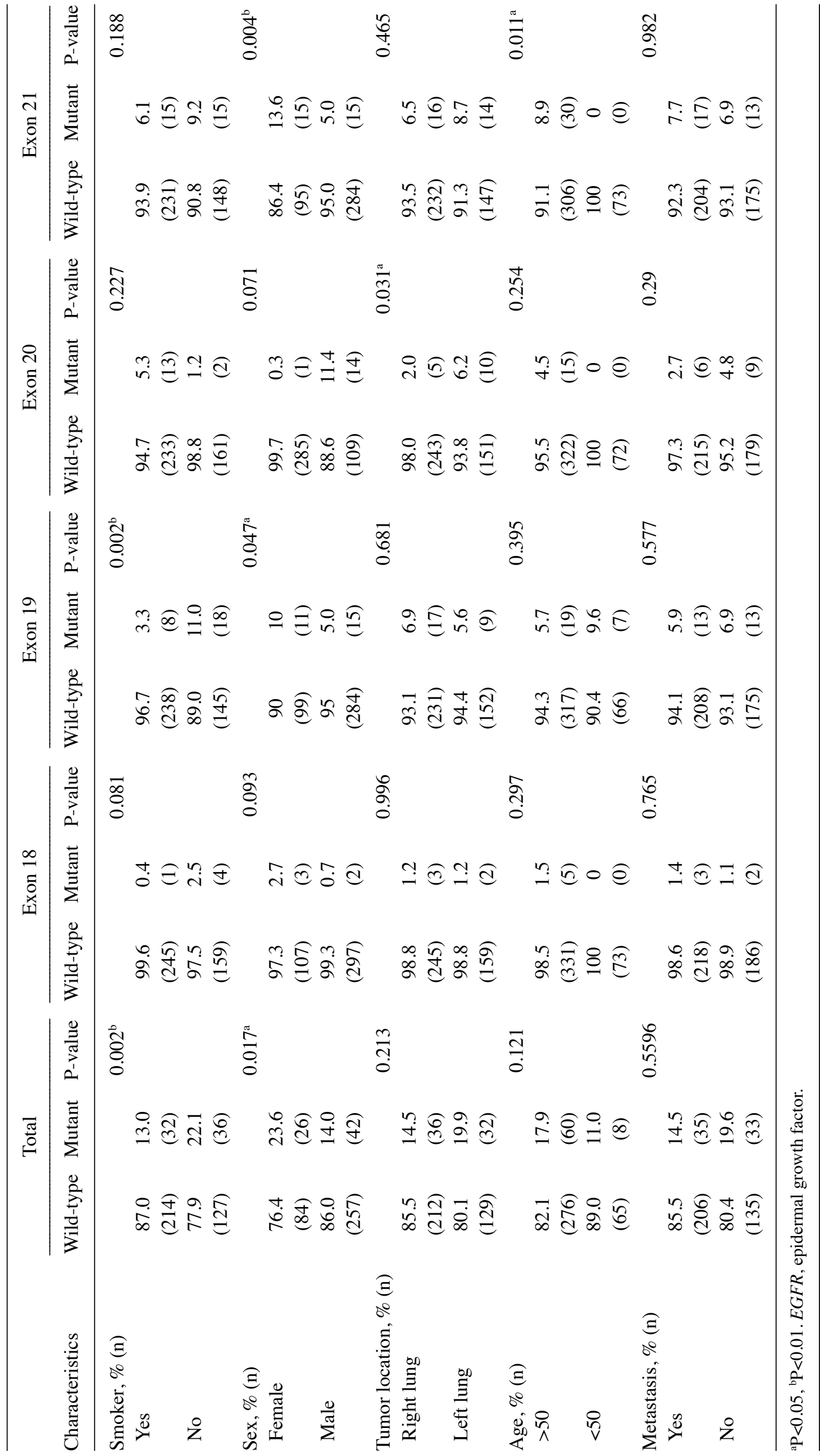


Table VI. Frequency of detected EGFR mutations in each exon.

\begin{tabular}{|c|c|c|}
\hline Exon & Mutation & Percentage (n) \\
\hline \multirow[t]{3}{*}{ Exon 18} & Gly719Arg ${ }^{\mathrm{a}}$ & (1) \\
\hline & Gly719Cys ${ }^{\mathrm{a}}$ & (1) \\
\hline & Gly719Ser $^{\mathrm{a}}$ & (3) \\
\hline \multirow[t]{6}{*}{ Exon 19} & Glu746_Ala750 del ${ }^{\mathrm{a}}$ & $65.4(17)$ \\
\hline & Leu747_Thr751 del & $11.5 \quad(3)$ \\
\hline & Leu747_Ser752 del & 7.7 (2) \\
\hline & Glu746_Ala750>IP & $7.7(2)$ \\
\hline & Glu746-Thr751del & $3.8(1)$ \\
\hline & Lys745_Glu746del & $3.8 \quad(1)$ \\
\hline \multirow[t]{9}{*}{ Exon 20} & Glu762ins; Ser768-Asp770dup & $6.7(1)$ \\
\hline & Glu762insEAFQ & $20 \quad(3)$ \\
\hline & Ser768Ile & $6.7 \quad(1)$ \\
\hline & Ser768-Asp770dup & $6.7(1)$ \\
\hline & Ser768-Asp770dup; T790M & $13.3 \quad(2)$ \\
\hline & Thr790Met $^{\mathrm{a}}$ & $33.3 \quad(5)$ \\
\hline & Val769Leu & $6.7 \quad(1)$ \\
\hline & Val769L; & $6.7 \quad(1)$ \\
\hline & Asn771His773dupAsnProHis & \\
\hline \multirow[t]{3}{*}{ Exon 21} & Asn826Ser & $3.3(1)$ \\
\hline & Leu858 Arg $^{\mathrm{a}}$ & $53.3(16)$ \\
\hline & Leu861Gln ${ }^{\mathrm{a}}$ & $43.3(13)$ \\
\hline
\end{tabular}

${ }^{\text {a }}$ Most common mutation. EGFR, epidermal growth factor.

\section{Discussion}

NSCLC is one of the most common types of cancer in the world, including in Turkey, and is the leading cause of cancer-associated deaths in both men and women worldwide (1). The incidence of NSCLC is higher amongst males and smokers $(19,20)$, a pattern which was also observed in the present study. Male patients accounted for $73.1 \%$ of all NSCLC patients and smokers accounted for $60.1 \%$ of all patients.

$E G F R$ is an important marker driving carcinogenesis and the response to definite EGFR tyrosine kinase inhibitors. EGFR mutations are used as predictive biomarkers to understand the clinical response to EGFR tyrosine kinase inhibitors, and $70-80 \%$ of patients have benefited from tyrosine kinase inhibitors based therapies. This reveals the clinical importance of $E G F R$ mutational status for therapeutic decision-making $(7,8)$. To the best of our knowledge, the present study represents the largest molecular epidemiological dataset of $E G F R$ mutation status in a Turkish population. Previous studies have reported that EGFR mutation frequency shows variability according to regional differences and ethnicity, and Turkey has a multiethnic population, due to its geographic location between Europe and Asia and its proximity to Middle-East region (21). Therefore, determining the genetic distribution of EGFR mutations, may have clinical relevance for therapeutic decision making.
In the present study, EGFR mutations were detected in $16.6 \%$ of patients, consistent with the frequency of European based studies, such as in Greek, Spain and Poland (22-25), but not consistent with previously published studies from Turkey and the Middle-East (Table VII) (26-30). Previous studies from Turkey, showed higher frequencies (44 and $42.6 \%$, respectively) in terms of overall mutation rates, and the primary reason underlying the difference may be due to the small cohorts used in the previous studies $(29,30)$. The overall EGFR mutation frequency was $47.9 \%$ in Asian patients and $19.2 \%$ in Western patients (8). Asian and Caucasian patients also have different molecular epidemiological data in terms of EGFR status (31).

The most common mutations were detected in exon 19 and 21 (6.4 and 7.3\%, respectively), consistent with previous studies; however, it has been shown that mutation frequencies can differ in EGFR exons $(32,33)$. The variations in EGFR mutation frequencies between countries are likely the result of differences in case selection for testing and case number of tested groups, smoking habits and ethnicity (34).

Detected mutations in exon 18 were all point mutations; Gly719Arg, Gly719Cys and Gly719Ser. All of these Gly719X mutations have been described as drug sensitizing mutations $(35,36)$. For exon 19, deletions were the most common mutations. In the present study, all mutations detected in exon 19 mutated patients were deletions and 2 patients had $>1$ mutation (indels). Deletions were generally localized to amino acids 745-752, and Glu746_Ala750 deletion was the most common deletion among the patients. Exon 19 deletions are drug sensitizing mutations and the most common type of mutation in exon $19(35,36)$. Exon 20, harbored most of the mutation types, including point mutations, duplications and insertions, and point mutations were the most common type of mutation in exon 20. Thr790Met was the most common mutation in exon 20 , and it has been previously described as a drug resistant mutation $(35,36)$. In exon 21 , only point mutations were detected, and Leu858Arg and Leu861Gln were the most common, which have both been described as drug sensitizing mutations. Leu858Arg was the most common type of mutation in the entire cohort, consistent with previous literature $(35,36)$.

Previous studies have shown a significant association between the clinicopathological characteristics of patients, such as smoking status and sex and the frequency of EGFR mutations in patients with NSCLC $(19,37)$. The present study observed similar results among Turkish patients with NSCLC patients compared with other populations. There was a higher frequency of $E G F R$ mutations in females compared with males and in never-smokers compared with smokers. In another Turkish population-based study, EGFR mutations were also more common in females and non-smokers (29). The same associations have been observed in different $E G F R$ exon mutations. Exon 19 mutation frequency was higher in females compared with males and in non-smokers compared with smokers. Exon 21 mutations were also significantly more common in females compared with males. Overall, $E G F R$ mutation patterns and their association with clinicopathological characteristics were similar across most of the common exon mutations (exon 19 and 21). Patients with EGFR 
Table VII. Frequency of EGFR mutation status by different countries.

\begin{tabular}{|c|c|c|c|c|c|c|c|c|}
\hline Author, year & Country & $\begin{array}{c}\text { Total } \\
\text { patients, } \mathrm{n}\end{array}$ & $\begin{array}{c}\text { Overall } \\
\text { EGFR } \\
\text { mutation, } \%\end{array}$ & $\begin{array}{l}\text { Exon } \\
18, \%\end{array}$ & $\begin{array}{l}\text { Exon } \\
19, \%\end{array}$ & $\begin{array}{l}\text { Exon } \\
20, \%\end{array}$ & $\begin{array}{l}\text { Exon } \\
21, \%\end{array}$ & (Refs.) \\
\hline Vázquez et al, 2016 & Spain & 184 & 13.6 & 0 & 44 & 8 & 48 & $(24)$ \\
\hline Szumera-Ciećkiewicz et al, 2013 & Poland & 273 & 10.6 & 3.4 & 55 & 10.3 & 32 & $(25)$ \\
\hline Papadopoulou et al, 2015 & Greece & 1.472 & 15.83 & 1.29 & 67.38 & 4.29 & 27.04 & $(22)$ \\
\hline Syrigos et al, 2018 & Greece & 575 & 15.7 & 2.2 & 59.6 & 11.2 & 29.2 & $(23)$ \\
\hline Bircan et al, 2014 & Turkey & 25 & 44 & 0 & 32 & 0 & 20 & $(29)$ \\
\hline Unal et al, 2013 & $\begin{array}{l}\text { Turkey } \\
\text { (Western region) }\end{array}$ & 48 & 42.6 & 0 & 38.9 & 50 & 11.1 & (30) \\
\hline Present study & Turkey $^{\mathrm{a}}$ & 409 & 16.6 & 7.35 & 38.23 & 22.06 & 44.12 & - \\
\hline Errihani et al, 2013 & Morocco & 137 & 21 & 7 & 69 & 3 & 21 & $(21)$ \\
\hline Fakhruddin et al, 2014 & Lebanon & 106 & 8.5 & 0 & 88.9 & 0 & 11.1 & $(26)$ \\
\hline Haghgoo et al, 2017 & Iran & 98 & 37 & 0 & 72.2 & 0 & 27.8 & $(27)$ \\
\hline Jazieh et al, 2015 & $\begin{array}{l}\text { Saudi Arabia, } \\
\text { The United Arab } \\
\text { Emirates and Qatar }\end{array}$ & 230 & 28.7 & 6.06 & 54.54 & 1.5 & 39.4 & (28) \\
\hline
\end{tabular}

${ }^{a}$ Results from the present study; 8 patients had double mutations. EGFR, epidermal growth factor receptor.

mutated tumors were more likely to have a tumor localized to the right lung, although this association was not significant, but there was an association between tumors localized in the left lung tumor and exon 20 mutation frequency. Patients with tumors localized to the left lung had a higher exon 20 mutation frequency. The present study is the first to report this association.

In summary, European based studies showed a mutation frequency of 10-15\% in EGFR, Middle Eastern based studies showed a mutation frequency of 21-37\%, and Asian population-based studies showed a heterogeneous mutation frequency of $27-62 \%$ (38-41). In the present study, the mutation frequency of EGFR among the Turkish population was $16.6 \%$, less than that of the Middle Eastern and East Asian based studies; and similar to European based studies. These results may assist in determining the incidence of $E G F R$ mutations amongst the different ethnicities present in Turkey, and warrant the design of genome wide-based collaborations that may reveal novel decision-making mutations in EGFR in patients with NSCLC. Favorable management of NSCLC includes genetic screening of tumor tissues for informative biomarkers which may be used for targeted therapy, therefore clinical results can be developed with pharmacogenetic screenings that highlight the heterogeneity of NSCLC.

\section{Acknowledgements}

We would like to thank Mrs. Nurcin Kayacik (Dokuz Eylul University Hospital, Molecular Oncology Laboratory) for her technical support during the tumor tissue collection process and preparation of DNA isolation.

\section{Funding}

This study was supported by Dokuz Eylul University-Scientific Research Projects (grant no. 2018.KB.SAG.097).

\section{Availability of data and materials}

The datasets used and/or analyzed during the present study are available from the corresponding author on reasonable request.

\section{Authors' contributions}

GCK and YB conceived and designed the study. GCK and AA performed the experiments. GCK, AA, TS and YB analyzed the data. OUU and IO collected the patient data. DG performed the pathological evaluation and tissue processing. HE analyzed the data. GCK, AA and TS wrote the manuscript. All authors have read and approved the final manuscript.

\section{Ethics approval and consent to participate}

The study was based on pathological archived material and was approved by Dokuz Eylul University, Non-invasive Researches Ethics Committee (Izmir, Turkey) (approval no. 300-GOA, 2011/28-03). Written informed consent was obtained from all patients.

\section{Patient consent for publication}

Not applicable. 


\section{Competing interests}

The authors declare that they have no competing interests.

\section{References}

1. Bray F, Ferlay J, Soerjomataram I, Siegel RL, Torre LA and Jemal A: Global cancer statistics 2018: GLOBOCAN estimates of incidence and mortality worldwide for 36 cancers in 185 countries. CA Cancer J Clin 68: 394-424, 2018.

2. Turkey Ministry of Health.CancerStatistics-2015Report.https://hsgm. saglik.gov.tr/depo/birimler/kanser-db/istatistik/ Turkiye_Kanser_ Istatistikleri_2015.pdf. Accessed February 28, 2020.

3. Shankar A, Dubey A, Saini D, Singh M, Prasad CP, Roy S, Bharati SJ, Rinki M, Singh N, Seth T, et al: Environmental and occupational determinants of lung cancer. Transl Lung Cancer Res 8 (Suppl 1): S31-S49, 2019.

4. Wu S, Zhu W, Thompson P and Hannun YA: Evaluating intrinsic and non-intrinsic cancer risk factors. Nat Commun 9: 3490, 2018.

5. Duma N, Santana-Davila R and Molina JR: Non-small cell lung cancer: Epidemiology, screening, diagnosis, and treatment. Mayo Clin Proc 94: 1623-1640, 2019.

6. Artal Cortés Á, Calera Urquizu L and Hernando Cubero J: Adjuvant chemotherapy in non-small cell lung cancer: State-of-the-art. Transl Lung Cancer Res 4: 191-197, 2015.

7. Benbrahim Z, Antonia T and Mellas N: EGFR mutation frequency in Middle East and African non-small cell lung cancer patients: A systematic review and meta-analysis. BMC Cancer 18: 891, 2018.

8. Dearden S, Stevens J, Wu YL and Blowers D: Mutation incidence and coincidence in non small-cell lung cancer: Meta-analyses by ethnicity and histology (mutMap). Ann Oncol 24: 2371-2376, 2013

9. Thomas R and Weihua Z: Rethink of EGFR in cancer with its kinase independent function on board. Front Oncol 9: 800, 2019

10. Kujtan L and Subramanian J: Epidermal growth factor receptor tyrosine kinase inhibitors for the treatment of non-small cell lung cancer. Expert Rev Anticancer Ther 19: 547-559, 2019.

11. Leal LF, de Paula FE, De Marchi P, de Souza Viana L, Pinto GDJ, Carlos CD, Berardinelli GN, Miziara JE, da Silva CM, Silva ECA, et al: Mutational profile of Brazilian lung adenocarcinoma unveils association of EGFR mutations with high Asian ancestry and independent prognostic role of KRAS mutations. Sci Rep 9: 3209, 2019.

12. Midha A, Dearden S and McCormack R: EGFR mutation incidence in non-small-cell lung cancer of adenocarcinoma histology: A systematic review and global map by ethnicity (mutMapII). Am J Cancer Res 5: 2892-2911, 2015.

13. World Medical Association: World medical association declaration of Helsinki: Ethical principles for medical research involving human subjects. JAMA 310: 2191-2194, 2013.

14. Calibasi G, Baskin Y, Alyuruk H, Cavas L, Oztop I, Sagol O, Atila K, Ellidokuz $\mathrm{H}$ and Yilmaz U: Molecular analysis of the KIT gene in gastrointestinal stromal tumors with novel mutations. Appl Immunohistochem Mol Morphol 22: 37-45, 2014.

15. Weyant GW, Wisotzkey JD, Benko FA and Donaldson KJ: BRAF mutation testing in solid tumors: A methodological comparison. J Mol Diagn 16: 481-485, 2014.

16. Bihl MP, Hoeller S, Andreozzi MC, Foerster A, Rufle A, Tornillo L and Terracciano L: KRAS mutation testing in colorectal cancer: Comparison of the results obtained using 3 different methods for the analysis of codons G12 and G13. Diagn Mol Pathol 21: 14-23, 2012

17. Dean AG, Sullivan KM and Soe MM: OpenEpi: Open source epidemiologic statistics for public health. www.openepi.com, Accessed February 28, 2020.

18. R Core Team: R: A language and environment for statistical computing. R Foundation for Statistical Computing, Vienna, Austria, 2012. ISBN 3-900051-07-0, URL http://www.R-project.org/

19. Hammoudeh ZA, Antonova O, Staneva R, Nikolova D, Kyuchukov Y, Penev A, Mintchev T, Koleva V, Hadjidekova S and Toncheva D: Detecting EGFR mutations in patients with non-small cell lung cancer. Balkan J Med Genet 21: 13-17, 2014.

20. Liam CK, Wahid MI, Rajadurai P, Cheah YK and Ng TS: Epidermal growth factor receptor mutations in lung adenocarcinoma in Malaysian patients. J Thorac Oncol 8: 766-772, 2013.
21. Errihani H, Inrhaoun H, Boukir A, Kettani F, Gamra L, Mestari A, Jabri L, Bensouda Y, Mrabti H and Elghissassi I: Frequency and type of epidermal growth factor receptor mutations in moroccan patients with lung adenocarcinoma. J Thorac Oncol 8: 1212-1214, 2013.

22. Papadopoulou E, Tsoulos N, Tsirigoti A, Apessos A, Agiannitopoulos K, Metaxa-Mariatou V, Zarogoulidis K, Zarogoulidis P, Kasarakis D, Kakolyris S, et al: Determination of EGFR and KRAS mutational status in Greek non-small cell lung cancer patients. Oncol Lett 10: 2176-2184, 2015.

23. Syrigos KN, Georgoulias V, Zarogoulidis K, Makrantonakis $\mathrm{P}$, Charpidou A and Christodoulou C: Epidemiological characteristics, EGFR status and management patterns of advanced non-small cell lung cancer patients: The Greek REASON Observational Registry Study. Anticancer Res 38: 3735-3744, 2018.

24. Vázquez S, Casal J, Afonso Afonso FJ, Fírvida JL, Santomé L, Barón F, Lázaro M, Pena C, Amenedo M, Abdulkader I, et al: VEGFR testing and clinical management of advanced NSCLC: A Galician Lung Cancer Group study (GGCP 048-10). Cancer Manag Res 8: 11-20, 2016.

25. Szumera-Ciećkiewicz A, Olszewski WT, Tysarowski A, Kowalski DM, Głogowski M, Krzakowski M, Siedlecki JA, Wągrodzki M and Prochorec-Sobieszek M: EGFR mutation testing on cytological and histological samples in non-small cell lung cancer: A Polish, single institution study and systematic review of European incidence. Int J Clin Exp Pathol 6: 2800-2812, 2013.

26. Fakhruddin N, Mahfouz R, Farhat F, Tfayli A, Abdelkhalik R, Jabbour M, Yehia L, Mahfoud Z and Zaatari G: Epidermal growth factor receptor and KRAS mutations in lung adenocarcinoma: A retrospective study of the Lebanese population. Oncol Rep 32: 2223-2229, 2014.

27. Haghgoo SM, Khosravi A,Mortaz E, Pourabdollah-Toutkaboni M, Seifi S, Sabour S and Allameh A: Prognostic value of rare and complex mutations in EGFR and serum levels of soluble EGFR and its ligands in non-small cell lung carcinoma patients. Clin Biochem 6: 293-300, 2017.

28. Jazieh AR, Jaafar H, Jaloudi M, Mustafa RS, Rasul K, Zekri J and Gasmelseed A: Patterns of epidermal growth factor receptor mutation in non-small-cell lung cancers in the Gulf region. Mol Clin Oncol 3: 1371-1374, 2015.

29. Bircan S, Baloglu H, Kucukodaci Z and Bircan A: EGFR and KRAS mutations in Turkish non-small cell lung cancer patients: A pilot study. Med Oncol 31: 87, 2014.

30. Unal OU, Oztop I, Calibasi G, Baskin Y, Koca D, Demir N, Akman T, Ellidokuz $\mathrm{H}$ and Yilmaz AU: Relationship between epidermal growth factor receptor gene mutations and clinicopathological features in patients with non-small cell lung cancer in western Turkey. Asian Pac J Cancer Prev 14: 3705-3709, 2013.

31. Zhang YL, Yuan JQ, Wang KF, Fu XH, Han XR, Threapleton D, Yang ZY, Mao C and Tang JL: The prevalence of EGFR mutation in patients with non-small cell lung cancer: A systematic review and meta-analysis. Oncotarget 7: 78985-78993, 2016

32. Tu HY, Ke EE, Yang JJ, Sun YL, Yan HH, Zheng MY, Bai XY, Wang Z, Su J, Chen $\mathrm{ZH}$, et al: A comprehensive review of uncommon EGFR mutations in patients with non-small cell lung cancer. Lung Cancer 114: 96-102, 2017.

33. Lund-Iversen M, Kleinberg L, Fjellbirkeland L, Helland $\AA$ and Brustugun OT: Clinicopathological characteristics of 11 NSCLC patients with EGFR-exon 20 mutations. J Thorac Oncol 7: 1471-1473, 2012.

34. Yatabe Y, Kerr KM, Utomo A, Rajadurai P, Tran VK, Du X, Chou TY, Enriquez ML, Lee GK, Iqbal J, et al: EGFR mutation testing practices within the Asia Pacific region: Results of a multicenter diagnostic survey. J Thorac Oncol 10: 438-445, 2015.

35. Pirker R, Herth FJ, Kerr KM, Filipits M, Taron M, Gandara D, Hirsch FR, Grunenwald D, Popper H, Smit E, et al: Consensus for EGFR mutation testing in non-small cell lung cancer: Results from a European workshop. J Thorac Oncol 5: 1706-1713, 2010.

36. Massarelli E, Johnson FM, Erickson HS, Wistuba II and Papadimitrakopoulou V: Uncommon epidermal growth factor receptor mutations in non-small cell lung cancer and their mechanisms of EGFR tyrosine kinase inhibitors sensitivity and resistance. Lung Cancer 80: 235-241, 2013. 
37. Lee B, Lee T, Lee SH, Choi YL and Han J: Clinicopathologic characteristics of EGFR, KRAS, and ALK alterations in 6,595 lung cancers. Oncotarget 7: 23874-23884, 2016.

38. Tomizawa Y, Iijima H, Sunaga N, Sato K, Takise A, Otani Y, Tanaka S, Suga T, Saito R, Ishizuka T, et al: Clinicopathologic significance of the mutations of the epidermal growth factor receptor gene in patients with non-small cell lung cancer. Clin Cancer Res 11: 6816-6822, 2005.

39. Shigematsu H, Lin L, Takahashi T, Nomura M, Suzuki M, Wistuba II, Fong KM, Lee H, Toyooka S, Shimizu N, et al Clinical and biological features associated with epidermal growth factor receptor gene mutations in lung cancers. J Natl Cancer Inst 97: 339-346, 2005.
40. Suda K, Onozato R, Yatabe Y and Mitsudomi T: EGFR T790M mutation: A double role in lung cancer cell survival? J Thorac Oncol 4: 1-4, 2009.

41. Siegelin MD and Borczuk AC: Epidermal growth factor receptor mutations in lung adenocarcinoma. Lab Invest 94: 129-137, 2014 